\title{
Exposure to EGF and 17 $\beta$-estradiol irreversibly affects the proliferation and transformation of MCF7 cells but is not sufficient to promote tumor growth in a xenograft mouse model upon withdrawal of exposure
}

\author{
SARA I. CUNHA ${ }^{1}$, MIN JIA ${ }^{2}$ and SERHIY SOUCHELNYTSKYI ${ }^{3}$ \\ ${ }^{1}$ Department of Immunology, Genetics and Pathology, Uppsala University, 75237 Uppsala; \\ ${ }^{2}$ Department of Biosciences and Nutrition, Karolinska Institutet, 14157 Stockholm, Sweden; \\ ${ }^{3}$ College of Medicine, Qatar University, Doha 2713, Qatar
}

Received March 13, 2018; Accepted June 18, 2018

DOI: $10.3892 /$ ijmm.2018.3737

\begin{abstract}
Epidermal growth factor (EGF) and estrogen are potent regulators of breast tumorigenesis. Their short-term actions on human breast epithelial cells have been investigated extensively. However, the consequence of a long-term exposure to EGF and estrogen remains to be fully elucidated. The present study examined the effects of long-term exposure to EGF and $17 \beta$-estradiol on the proliferation, transformation, expression of markers of stemness, and tumorigenesis of MCF7 human breast adenocarcinoma cells. Exposure to EGF and/or $17 \beta$-estradiol irreversibly enhanced the proliferation rate of MCF7 cells, even following withdrawal. However, in a mouse xenograft experiment, no significant difference in tumor volume was observed between tumors derived from cells exposed to EGF, $17 \beta$-estradiol or EGF + 17 $\beta$-estradiol. Immunohistochemistry performed on tumors derived from $17 \beta$-estradiol-exposed cells revealed reduced cell proliferation and vessel scores, according to the results obtained using Ki67 and von Willebrand factor staining, respectively. The EGFand/or 17 $\beta$-estradiol-treated cells exhibited an increased ratio of cluster of differentiation (CD) $44^{+} / \mathrm{CD} 24-$ cells and enhanced ability to form mammospheres. Furthermore, the long-term exposure of MCF7 cells to EGF and 17 $\beta$-estradiol altered their responsiveness to short-term stimulatory or inhibitory
\end{abstract}

Correspondence to: Professor Serhiy Souchelnytskyi, College of Medicine, Qatar University, Building H12, Al Jamiaa Street, Doha 2713, Qatar

E-mail: serhiy@qu.edu.qa

Abbreviations: EGF, epidermal growth factor; vWF, von Willebrand factor; TGF $\beta$, transforming growth factor- $\beta$; ER, estrogen receptor; DCIS, ductal carcinoma in situ; ECM, extracellular matrix

Key words: epidermal growth factor, $17 \beta$-estradiol, breast cancer, stemness, xenograft treatments with EGF, $17 \beta$-estradiol, transforming growth factor- $\beta 1$ (TGF $\beta 1$ ), Iressa and SB431542. Therefore, the findings indicated that sustained exposure of MCF7 cells to EGF and/or 17 $\beta$-estradiol resulted in enhanced cell proliferation and mammosphere formation, an increased ratio of $\mathrm{CD}_{4} 4^{+} / \mathrm{CD} 24$ cells, and altered responses to short-term treatments with EGF, $17 \beta$-estradiol, TGF $\beta 1$, and drugs inhibiting these signaling pathways. However, this sustained exposure was not sufficient to affect tumor take or volume in a xenograft mouse model.

\section{Introduction}

Human breast epithelial cells are constantly exposed to polypeptide growth factors and steroid hormones as part of their physiological control. The levels of epidermal growth factor (EGF) and estrogen have an impact on cell physiology, including cell proliferation rate, differentiation and migration (1-5). The exposure of cells to elevated levels of EGF and estradiol for a prolonged period of time may irreversibly affect their physiology, which may consequently impact on cell carcinogenic transformation.

Tumorigenesis is a complex process involving alterations of multiple genes, proteins and regulatory pathways $(6,7)$. In breast cancer, the overexpression of epidermal growth factor receptor (EGFR) in the primary tumor correlates with increased metastatic dissemination and aggressive tumor progression (8). In total, $>70 \%$ of breast cancer tumors express high levels of estrogen receptor- $\alpha(E R \alpha)$, and a large number of these tumors require estrogen to support cancer cell proliferation and tumor progression (9). As the EGFR and estrogen signaling pathways are closely associated with the development of breast cancer, they are targets for the treatment of breast cancer $(10,11)$.

The EGF and estrogen signaling pathways share a number of intracellular signaling mechanisms due to crosstalk (10-12). The inverse correlation observed between the expression levels of EGFR and ER $\alpha$ has been explained by compensatory mechanisms, which are activated in malignant cells in order to maintain a high proliferative status. 
When one of the above receptors is upregulated or downregulated, the expression of the other receptor compensates for this alteration (12). It has been reported that EGF- and ER $\alpha$-dependent transcription may operate in parallel, although with a marked overlap in the affected genes (13). Estrogen may also control the downregulation of EGFR (10). However, the exact molecular mechanisms of the crosstalk remain to be fully elucidated. In addition, how long-term exposure to EGF and estrogen may affect the carcinogenic properties of cells remains unclear.

Breast cancer stem cells are defined as self-renewing cells required to initiate a tumor and drive tumor growth when transplanted into mice $(14,15)$. In human breast cancer, cancer stem cells show a cluster of differentiation (CD) $44^{+} / \mathrm{CD} 24$ pattern of surface markers (16). This population of cells exhibits the ability to form three-dimensional mammospheres under low-adherence conditions and exhibit increased resistance to chemotherapeutic compounds (14-17). The EGFR signaling pathway has been implicated in the self-renewal of breast cancer stem cells (18). It has been reported that the EGFR tyrosine kinase inhibitor Iressa significantly decreases the formation of mammospheres by cells derived from a ductal carcinoma in situ (19). A number of studies have reported that estrogen treatment may expand the pool of breast cancer stem cells $(20,21)$. The present study hypothesized that, if prolonged exposure to EGF and estradiol changes the physiology of breast cancer cells, then it may also modulate cell responsiveness to anticancer drugs. The results revealed that sustained exposure of conditionally tumorigenic MCF7 human breast adenocarcinoma cells to EGF and $17 \beta$-estradiol led to the generation of cells with increased proliferation rate, increased $\mathrm{CD} 44^{+} / \mathrm{CD} 24^{-}$cell fraction population and a different pattern of response to therapeutic drugs, including Iressa, tamoxifen and the transforming growth factor (TGF) $\beta$ type I receptor kinase inhibitor SB431542, compared with non-exposed control cells. The mouse xenograft experiments revealed that these changes in cell physiology were not sufficient to ensure additional tumor development in immunocompromised mice upon withdrawal of treatment.

\section{Materials and methods}

Cell culture. The MCF7 human breast adenocarcinoma cell line was purchased from the American Type Culture Collection (Rockville, MD, USA; HTB-22 ${ }^{\mathrm{TM}}$ ) and cultured in Dulbecco's modified Eagle's medium (DMEM; Gibco; Thermo Fisher Scientific, Inc., Waltham, MA, USA) supplemented with $10 \%$ fetal bovine serum (FBS; Sigma-Aldrich, Merck KGaA, Darmstadt, Germany), $100 \mathrm{U} / \mathrm{ml}$ penicillin, $100 \mu \mathrm{g} / \mathrm{ml}$ streptomycin and $2 \mathrm{mM}$ glutamine. The cells were maintained in a humidified atmosphere with $5 \% \mathrm{CO}_{2}$ at $37^{\circ} \mathrm{C}$. To generate cell clones exposed to EGF, estrogen and EGF + estrogen, the MCF7 cells at an initial density of $1 \times 10^{6}$ cells/plate were grown on agarose-coated culture dishes with $5 \mathrm{ng} / \mathrm{ml}$ of EGF (Sigma-Aldrich; Merck KGaA), $5 \mathrm{nM}$ of 17ß-estradiol (Sigma-Aldrich; Merck KGaA) or $5 \mathrm{ng} / \mathrm{ml}$ of EGF $+5 \mathrm{nM}$ $17 \beta$-estradiol. Agarose coating prevented the attachment of cells to the plate. After 4 weeks, the cells were transferred to 96-well plates coated with agarose. The growing clones of cells were expanded, and 12 clones for each of the treatment conditions were randomly selected for evaluation of their proliferation status. For subsequent experiments, clones that represented the average proliferation status of the initial clones were selected, in addition to the 12 randomly selected clones (data not shown). The total time of cell exposure to EGF and/or $17 \beta$-estradiol was 40-42 days, prior to the random selection of 12 initial clones, from which other clones were selected for the mouse model and subsequent experiments. The selected clones were cultured and analyzed on regular culture dishes without agarose coating.

MTT assay. Cell proliferation was measured using the CellTiter $96^{\circledR}$ Non-Radioactive Cell Proliferation assay (Promega Biotech AB, Stockholm, Sweden). The MTT assay was performed according to the manufacturer's protocol. In brief, 1,000 cells were seeded per well in 96-well plates in triplicate, treated with $5 \mathrm{ng} / \mathrm{ml}$ EGF (Sigma-Aldrich; Merck KGaA), $5 \mathrm{nM}$ 17ß-estradiol (Sigma-Aldrich; Merck KGaA) or $5 \mathrm{ng} / \mathrm{ml} \mathrm{EGF}+5 \mathrm{nM} 17 \beta$-estradiol, incubated in complete DMEM culture medium for $48 \mathrm{~h}$, and then subjected to the MTT assay. The formazan crystals were dissolved in DMSO. The absorbance at $570 \mathrm{~nm}$ was recorded using a plate reader. Statistical significance of observed differences was evaluated using a one-way analysis of variance (ANOVA) with Tukey's honest significant difference (HSD) test.

Colony formation assay. Colony formation assays were performed in 6-well plates. Briefly, a bottom layer consisting of $0.5 \%$ agar in complete culture medium was poured and, once solidified, was covered by a layer containing $0.3 \%$ agar and 2,000 cells $/ w e l l$. Treatments were performed by the addition of $5 \mathrm{ng} / \mathrm{ml}$ EGF (Sigma-Aldrich; Merck KGaA, Darmstadt, Germany), 5 nM 17ß-estradiol (Sigma-Aldrich; Merck KGaA, Darmstadt, Germany) or $5 \mathrm{ng} / \mathrm{ml}$ EGF $+5 \mathrm{nM} 17 \beta$-estradiol to the medium in the top layer on experimental day 1 , considering the total volume of medium in the well. The plates were placed in the incubator, and the colonies were counted under a light microscope LeicaDHil (Leica Microsystems GmbH, Wetzlar, Germany) following 2 weeks of incubation. Treatments were introduced on day 1 of experiment, and the cells were under treatment for the 2 weeks of incubation. Colonies containing a minimum of 64 cells were counted. The statistical significance of observed differences was evaluated using a one-way ANOVA with Tukey's HSD test.

Mouse xenograft tumorigenesis assay. All experiments on mice were performed according to Swedish and International guidelines (ethical approval no. C123/6, granted by the Uppsala Animal Tests Committee of the Uppsala Court, Uppsala, Sweden). Five severe combined immunodeficiency (SCID) mice (females, 12 weeks of age, housed in pathogen-free conditions, at $25^{\circ} \mathrm{C}, 12$-h day/night cycle, food and water ad libitum (free access); Charles Rivers Laboratory, Worcester, MA, USA) were injected subcutaneously in the flank with selected and tested cell clones per condition, and with parental MCF7 cells, and six mice were injected with wild-type cells. Each mouse received $5 \times 10^{6}$ cells/injection in a volume of $100 \mu 1$ suspended at a 1:1 ratio in PBS and Matrigel (BD Pharmingen, San Diego, CA, USA) in the mouse flanks. 
The mice were monitored twice a week for overall health and tumor formation. The tumor diameters were measured with calipers, and the tumor volume in $\mathrm{mm}^{3}$ was calculated using the following formula: Volume $=$ width $^{2} \mathrm{x}$ length $\mathrm{x} 0.5$. The mice were sacrificed at 29 weeks. All the tumors were excised, fixed in $4 \%$ paraformaldehyde for $24 \mathrm{~h}$ at $4^{\circ} \mathrm{C}$ and embedded in paraffin for analysis.

Immunohistochemistry. Paraffin-embedded sections of $5-\mu \mathrm{m}$ were deparaffinized, rehydrated and subjected to antigen retrieval by incubation in citrate buffer $(\mathrm{pH}$ 6; Dako, Glostrup, Denmark) twice for $7 \mathrm{~min}$ at $95^{\circ} \mathrm{C}$. Quenching of endogenous peroxidase was performed by incubation in $3 \%$ $\mathrm{H}_{2} \mathrm{O}_{2}$ in PBS for $10 \mathrm{~min}$ at room temperature. Upon washing in PBS, the slides were incubated in $20 \%$ normal goat serum (cat. no. S-1000; Vector Laboratories, Inc., Burlingame, CA, USA) in PBST (PBS with 0.1\% Tween-20) for blocking. The tumor sections were then incubated with anti-human Ki-67 clone MIB1 antibody (cat. no. M7240; Dako) diluted 1:250 and with anti-von Willebrand factor (vWF) antibody (cat. no. ab6994; Abcam, Cambridge, MA, USA) diluted 1:750 in blocking buffer overnight at $4{ }^{\circ} \mathrm{C}$. Following washing with PBST, a secondary biotinylated universal antibody (horse anti-mouse/rabbit IgG; cat. no. BA-1400; Vector Laboratories, Inc.) at dilution 1:50 was added and incubated for $45 \mathrm{~min}$ in room temperature. The slides were stained using a Vectastain Elite ABC kit (Vector Laboratories, Inc., Burlingame, USA) following the manufacturer's protocol, and then counterstained with Mayer's hematoxylin, dehydrated and mounted with Mountex (SouthernBiotech, Birmingham, AL, USA). Images of the stained tissues were captured using a Leica DFC camera and images were acquired with Leica QWin version 3 software (Leica Microsystems Imaging Solutions, Ltd., Cambridge, UK). The proliferative score was measured as the ratio of MIB1-stained cells to the total number of cells. The vessel score was measured as the number of vessels stained with anti-vWF antibody per tumor section.

Flow cytometry. A total of $1 \times 10^{6}$ cells were used per experimental condition. The cells were collected, washed twice in cold PBS $+1 \%$ bovine serum albumin (BSA: Sigma-Aldrich; Merck KGaA) and incubated at $4^{\circ} \mathrm{C}$ with either 1:25-diluted anti-CD44-fluoresein isothiocyanate antibody (1:25; cat. no. 555478; clone G44-26; BD Pharmingen) or anti-CD24-allophycocyanin antibody (1:25; cat. no. 561646; clone ML5; BD Pharmingen) in PBS + $1 \%$ BSA for $30 \mathrm{~min}$ in the dark. Subsequently, the cells were washed twice in cold PBS $+1 \%$ BSA and resuspended in $400 \mu \mathrm{l}$ cold PBS $+1 \%$ BSA for flow cytometric analysis.

Mammosphere assays. The cells were trypsinized, mechanically separated and passed through $40-\mu \mathrm{m}$ strainers to obtain a single cell suspension. Subsequently, the cells were plated at a density of 5,000 or 1,000 cells in $4 \mathrm{ml}$ per well in super-low-attachment plates. Treatments were added on day 1 upon seeding of cells, and continued for 2 weeks as follows: $\mathrm{EGF}$ at $5 \mathrm{ng} / \mathrm{ml}, 17 \beta$-estradiol at $5 \mathrm{nM}, \mathrm{TGF} \beta 1$ at $10 \mathrm{ng} / \mathrm{ml}$, and Iressa, tamoxifen and SB431542 at $10 \mu \mathrm{M}$. The numbers of mammospheres formed were counted following 2 weeks of incubation with these drugs.
Statistical analysis. Significant differences were calculated using a one-way ANOVA with Tukey's HSD test. Data was analyzed using online software (www.icalcu.com online test) and with IBM SPSS software version 25 (IBM Corp., Armonk NY, USA). Results were presented as the mean \pm standard deviation. $\mathrm{P}<0.05$ was considered to indicate a statistically significant difference.

\section{Results}

Exposure to EGF and/or $17 \beta$-estradiol enhances the proliferation rate of MCF7 cells. Following exposure of MCF7 cells to $17 \beta$-estradiol and/or EGF for 40-42 days, 12 clones per experimental condition were randomly collected. These clones were subjected to an MTT proliferation assay, and representative clones were used for subsequent experiments (data not shown). Prior to the proliferation experiments, EGF and $17 \beta$-estradiol were removed, and the cells were cultured in a standard culture medium without EGF or $17 \beta$-estradiol for two passages $(\sim 1$ week). The proliferation rate of the cells was then measured. Control cells underwent the same manipulations as the EGF and 17 $\beta$-estradiol-exposed cells. To evaluate whether the selection procedure by itself had an impact on the MCF7 cells, parental MCF7 cells were also included in the analysis. The parental cells were grown under standard culturing conditions as an adherent culture, and were not subjected to a substrate-independent selection.

The results indicated that cells exposed to EGF and/or $17 \beta$-estradiol exhibited a significantly enhanced rate of cell proliferation, whereas the control cells only exhibited a marginal increase in proliferation rate (Fig. 1A). These cell clones were used in all subsequent experiments. The prolonged exposure to EGF and/or 17 $\beta$-estradiol resulted in enhanced proliferation rates in vitro.

Substrate-independent growth is one of the key features of transformed cells; these cells do not require attachment to a substrate for proliferation. A soft agar colony formation assay was used to analyze the ability of cells to grow unattached to a surface. It was observed that the control and EGF- and/or 17 $\beta$-estradiol-exposed cells exhibited an enhanced ability to form colonies, compared with the parental cells (Fig. 1B). The difference between the parental and control cells may be due to the selection of control cells in the absence of adherence, whereas the parental cells were maintained as an adherent culture. Between the various selection conditions, the observed differences were not significant $(\mathrm{P}>0.05)$, the colonies did not differ significantly in their shapes, and no significant spreading of cells from the colonies observed (Fig. 1B). This higher level of colony formation in semi-solid medium may have resulted from the effect of the substrate-independent selection of cells during drug exposure (Fig. 1B). The proliferation-stimulating effect of the various treatments was observed when the cells were grown as a two-dimensional culture (Fig. 1A).

EGF-and/or 17 $\beta$-estrogen-exposed cells do not exhibit enhanced tumor formation ability in a xenograft mouse model. To investigate whether long-term exposure to EGF and/or $17 \beta$-estradiol affects the ability of cells to form tumors in vivo, $5 \times 10^{6}$ exposed cells were inoculated in both flanks of 
A

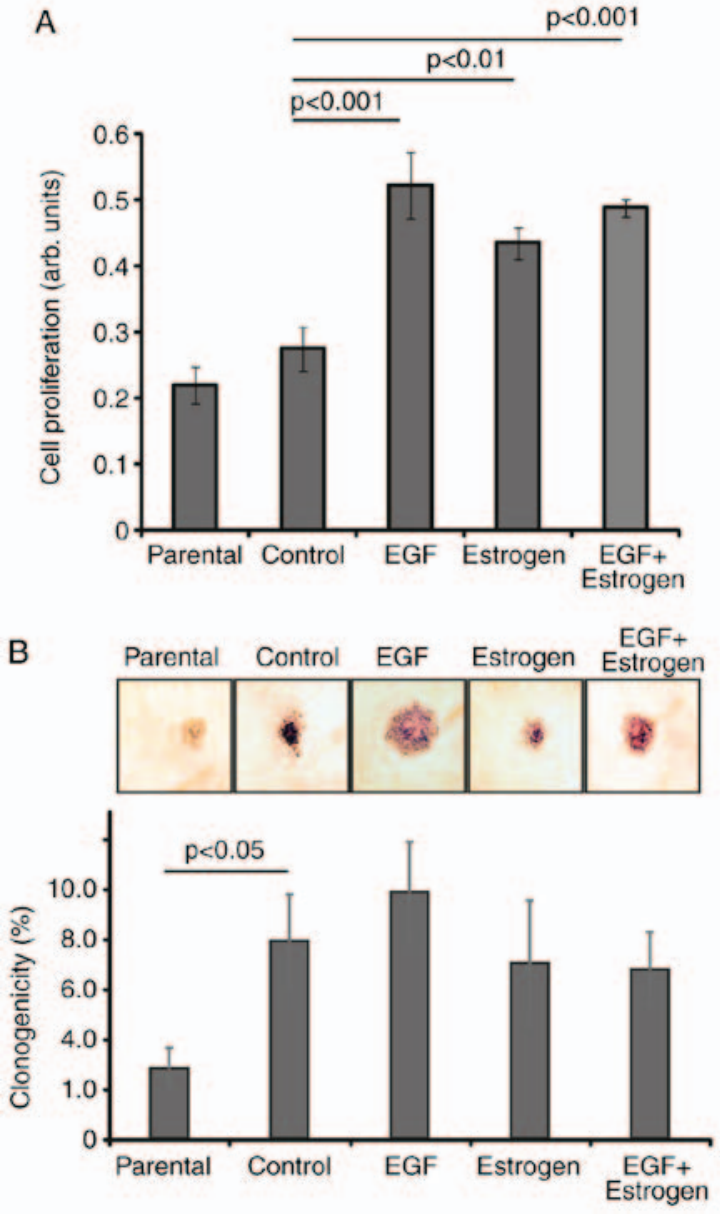

Figure 1. Prolonged exposure to EGF and $17 \beta$-estradiol increases the rate of proliferation of MCF7 cells. (A) MCF7 cell clones were generated following culture in anchorage independence on agarose and exposure to EGF and/or $17 \beta$-estradiol, alone or in combination. Cell proliferation was measured using an MTT assay. Statistical significance of differences was evaluated using a one-way ANOVA with Tukey's HSD. The experiment with representative clones is shown of five performed experiments. (B) Soft agar colony formation assay was performed with MCF7 cells exposed to treatments with EGF and/or 17 $\beta$-estradiol, alone or in combination, as indicated. Statistical significance of differences was evaluated using a one-way ANOVA with Tukey's HSD Images show examples of colonies formed by the cells, to illustrate shapes of colonies formed (magnification, $\mathrm{x} 400$ ). Representative results of three experiments are shown. EGF, epidermal growth factor.

each mouse ( $n=5$ SCID mice per condition; $n=6$ mice with non-exposed control cells). The tumor take, growth and the overall state of the mice were monitored every second day for 29 weeks. It was observed that three of the five mice injected with parental MCF7 cells developed tumors, whereas all six mice injected with control cells, all five mice injected with cells exposed to EGF or $17 \beta$-estradiol, and four of the five mice injected with cells exposed to EGF $+17 \beta$-estradiol presented with tumors (Fig. 2A). The volume of the tumors collected from the injection sites was also measured (Fig. 2B). No significant difference in volume was observed among the tumors derived from cells subjected to different exposures.

To examine whether the molecular and functional features of the cells in the xenograft tumors had changed, the tumor sections were stained for proliferative status by Ki-67 staining, whereas the vessel density and apoptosis were evaluated with the vascular marker vWF and a terminal deoxynucleotidyl transferase dUTP nick end labeling (TUNEL) assay, respectively.

The Ki-67 protein is a nuclear marker of proliferation (22). To investigate the cell proliferation rates, immunohistochemistry was performed by staining the collected mouse tumors with the anti-Ki-67 antibody MIB1 (Fig. 2C). Cell proliferation was scored based on the intensity and frequency of staining (Fig. 2D). The anti-Ki-67 immunohistochemistry revealed higher overall staining of cells in tumors derived from control and EGF-exposed cells, and lower staining of cells in tumors derived from $17 \beta$-estradiol-exposed cells, compared with the staining of tumors derived from parental MCF7 cells. The overall proliferation score revealed that tumors from the control and EGF-exposed groups exhibited the highest proliferation score, at 80 and $70 \%$, respectively. Tumors from the EGF and $17 \beta$-estradiol-exposed cells exhibited marginally higher Ki-67 staining than the parental cells, at 50, vs. $40 \%$, respectively. However, tumors from the 17ß-estradiol-exposed cells exhibited only $20 \%$ positive staining for Ki-67 (Fig. 2D).

vWF is a glycoprotein that mediates platelet adhesion to the sub-endothelium at sites of vascular injury, and binds and stabilizes factor VIII in the blood $(23,24)$. vWF appears to be expressed exclusively in endothelial cells, where it exhibits a granular pattern of reactivity. vWF is commonly used as an immunohistochemical marker of endothelial cells $(23,24)$. To evaluate the angiogenic status of cells within the collected tumors, immunohistochemistry for vWF was performed and vessel density was analyzed in the present study (Fig. 2E). The tumors from the control, EGF-exposed and EGF $+17 \beta$-estradiol-exposed cells exhibited significantly enhanced angiogenesis compared with that of the parental group, with an increase in vessel density of $>2.8$-fold for the control and EGF-exposed cells, and a 3.5-fold increase for the EGF $+17 \beta$-estradiol exposed cells. The tumors derived from $17 \beta$-estradiol-exposed cells exhibited decreased angiogenesis by $33 \%$ compared with that of tumors derived from parental cells (Fig. 2F). No significant cell death was observed in tumors stained with TUNEL (data not shown). Therefore, the xenograft mouse study revealed that tumor volume and tumor take did not differ among tumors formed by cells exposed to EGF and/or 17 $\beta$-estradiol. However, tumors formed by cells exposed to $17 \beta$-estradiol exhibited decreased expression of the proliferation marker Ki-67 and decreased vessel formation.

EGF and 17 $\beta$-estradiol exposure increases the breast cancer stem cell-like pool. To examine whether exposure to EGF and/or 17 $\beta$-estradiol affects the number of breast cancer stem cells, the proportion of stem-like cells was evaluated by flow cytometry and mammosphere formation assays. It was observed that, upon EGF, 17 $\beta$-estradiol, and EGF $+17 \beta$-estradiol exposure, the proportion of $\mathrm{CD} 44^{+} / \mathrm{CD} 24-$ cancer stem-like cells was $\sim 5$-, 3 - and 3-fold higher, respectively, than that of parental cells. No significant change in the proportion of $\mathrm{CD} 44^{+} / \mathrm{CD} 24^{-}$cells was detected in the control cells compared with the parental cells (Fig. 3A). This suggested that the change in expression of $\mathrm{CD} 44^{+} / \mathrm{CD} 24$ markers was attributed to the long-term treatments.

Mammosphere formation is indicative of cell transformation and is associated with the degree of stemness exhibited 
A
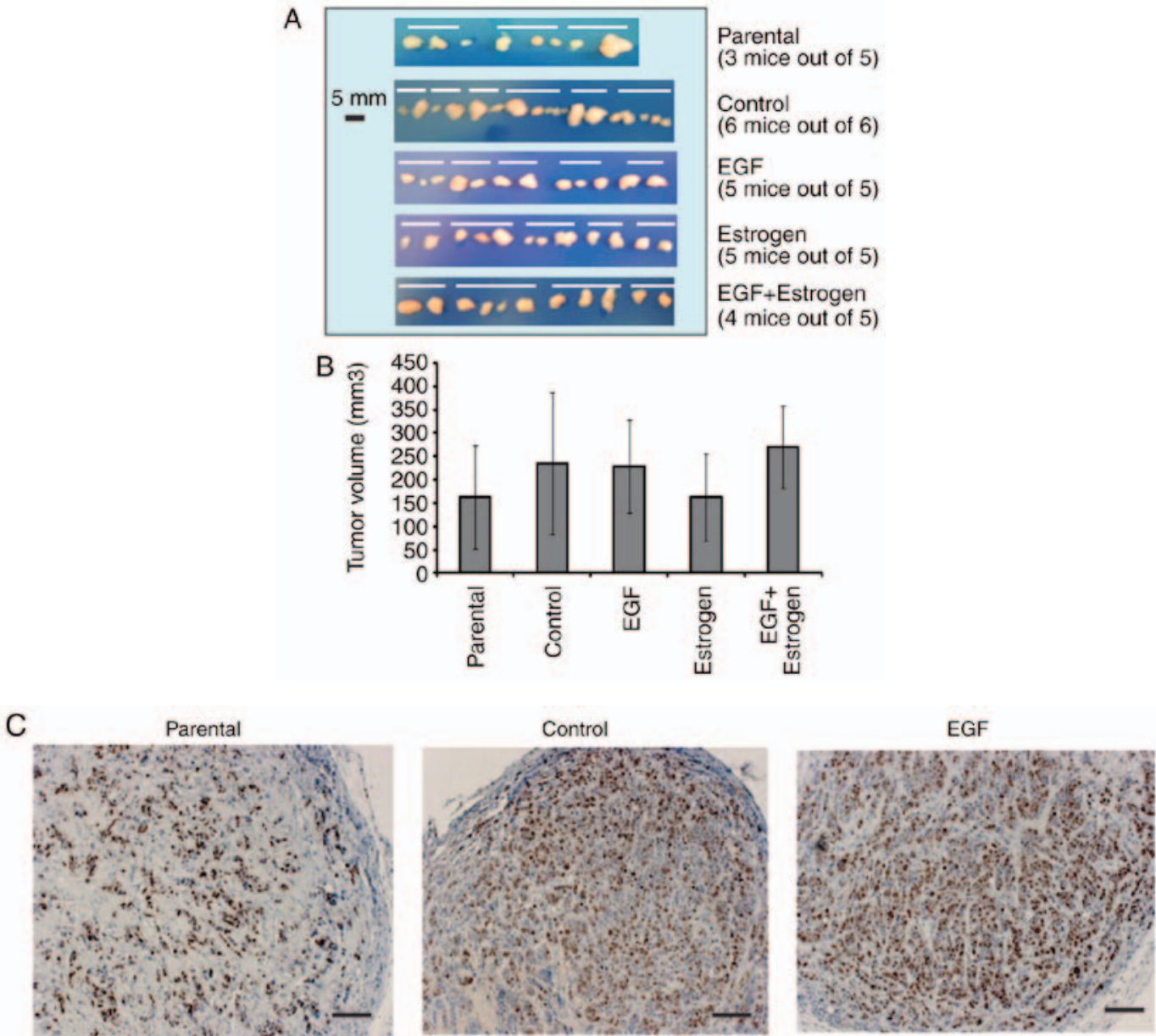

Estrogen

EGF+Estrogen
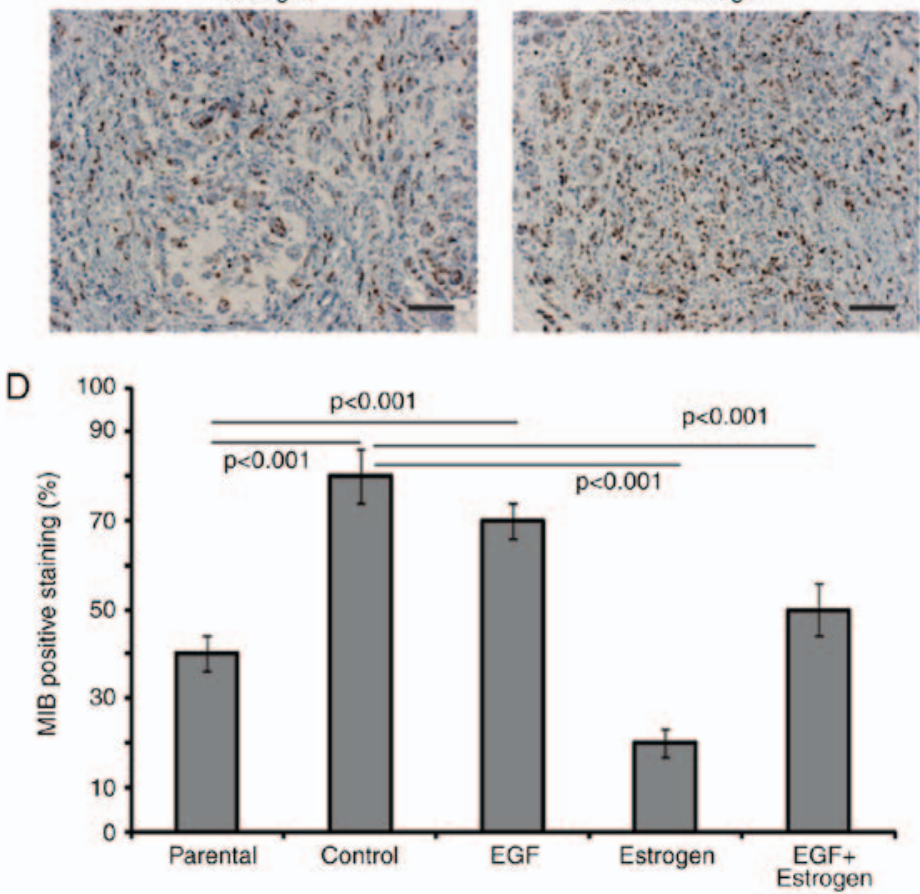

Figure 2. Tumorigenicity of MCF7 cell clones in the mice xenograft assay. (A) No significant difference in tumor take was found between different clones. The tumor take was calculated following retrieval of the tumors from the mice. The images show retrieved tumors from the mice, with white lines indicating tumors retrieved from the same mouse. In certain mice and in flanks, 2-3 tumors formed in the same injection site. Scale bar=5 mm. (B) Tumor volumes did not differ between experimental conditions. Tumor(s) formed in the same injection site were considered. (C) Immunohistochemical staining with MIB1 antibodies revealed that the tumors formed by the EGF- and 17ß-estradiol-exposed cells showed higher proliferation rate. Representative regions of the sections are shown. Scale bar=200 $\mu \mathrm{m}$. (D) Quantification of MIB1 staining (Ki-67 expression) in retrieved tumors is shown as the percentage of positive cells. Statistical significance of differences was evaluated using a one-way ANOVA with Tukey's HSD (All P<0.001). Statistical significance of differences was evaluated using a one-way ANOVA with Tukey's HSD (all P<0.001). Annotations in the panels indicate parental and control cells and clones of cells exposed to EGF and/or $17 \beta$-estradiol. EGF, epidermal growth factor. 


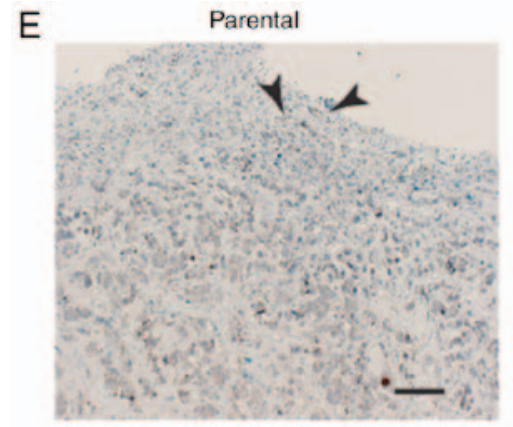

Estrogen

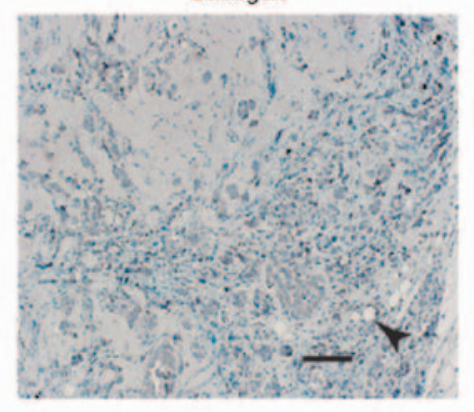

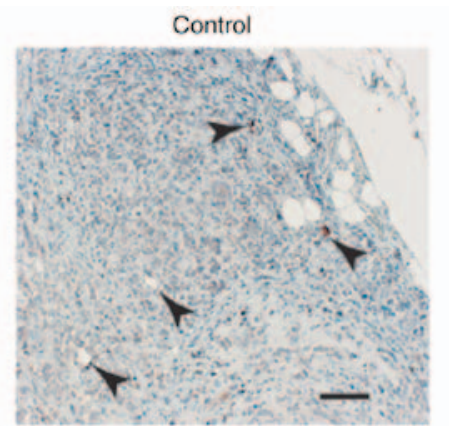

EGF+Estrogen

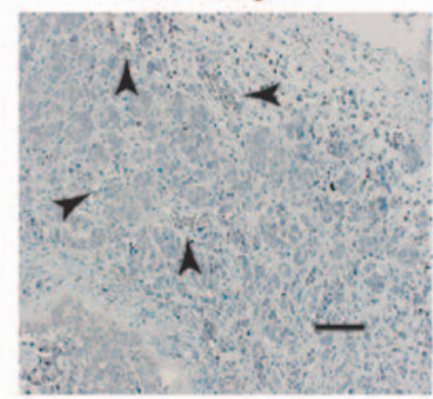

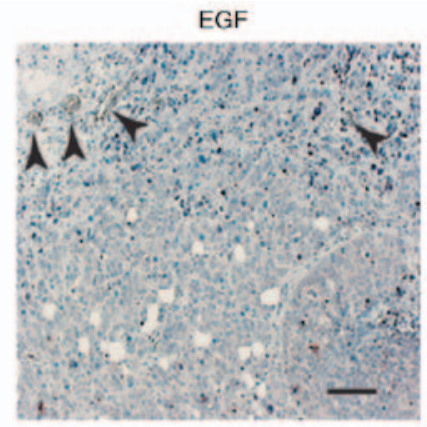
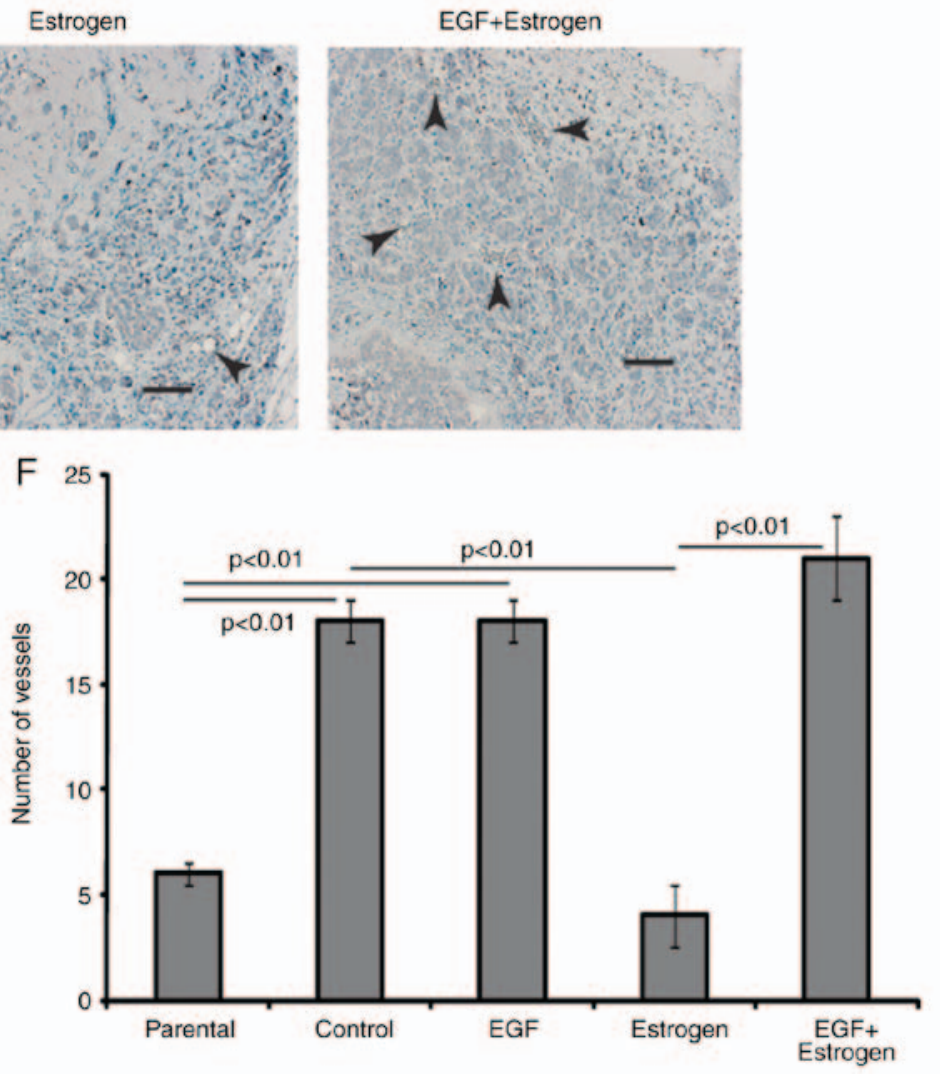

Figure 2. Continued. Tumorigenicity of MCF7 cell clones in the mice xenograft assay. (E) Immunohistochemical staining with vWF antibodies showed formation of vessels in the tumors formed by the EGF- and 17ß-estradiol-exposed cells. Arrowheads indicates vessels. Representative regions of the sections are shown. Scale bar $=200 \mu \mathrm{m}$. (F) Vessel scores were calculated following evaluation of vWF staining in the sections. Statistical significance of differences was evaluated using a one-way ANOVA with Tukey's HSD (all P<0.001). Annotations in the panels indicate parental and control cells and clones of cells exposed to EGF and/or 17ß-estradiol. EGF, epidermal growth factor; vWF, von Willebrand factor.

by the cells $(25,26)$. The present study observed that the EGF, $17 \beta$-estradiol and EGF $+17 \beta$-estradiol-exposed cells formed 6-, 3- and 3.5-fold higher numbers of mammospheres, respectively, than the control cells (Fig. 3B). The control cells exhibited the same low level of mammosphere formation as the parental cells (Fig. 3B). The enhanced proportion of $\mathrm{CD} 44^{+} / \mathrm{CD} 24^{-}$cells and the increase in mammosphere formation suggested that exposure to EGF and/or $17 \beta$-estradiol promoted an increase of cells with cancer stem cell-like characteristics.

EGF and $17 \beta$-estradiol exposure modulates mammosphere formation in response to treatments with Iressa, tamoxifen and SB431542. As prolonged exposure to EGF and/or $17 \beta$-estradiol altered the physiology of MCF7 cells, the effects of Iressa, tamoxifen and SB431542 on the cells were further examined. These compounds are inhibitory agents targeting EGF, estrogen, and TGF $\beta$ signaling, respectively (27-30). The mammosphere formation capacity of cells treated with EGF, $17 \beta$-estradiol, TGF $\beta 1$, and the inhibitors of the corresponding signaling pathways, Iressa, tamoxifen and SB431542, was evaluated (Fig. 4A-C). It was observed that the parental and control cells had similar pattern of responses, suggesting that the selection in non-adherent conditions preserved the responsiveness mechanisms of the cells. By contrast, the cells exposed to $17 \beta$-estradiol had a lower amplitude of response to treatments compared with the other cells. Tamoxifen was the only drug that exhibited a consistent inhibitory effect in all the cells evaluated, which is consistent with the ER-positive status of MCF7 breast cancer cells (31). Iressa inhibited mammosphere formation in the EGF and EGF + 17 $\beta$-estradiol-exposed cells. Exposure to EGF resulted in an overall increase of cell proliferation, which was inhibited upon treatment with $17 \beta$-estradiol, Iressa, tamoxifen and SB431542. Only TGF $\beta 1$ stimulated mammosphere formation in the EGF-treated cells. 
A

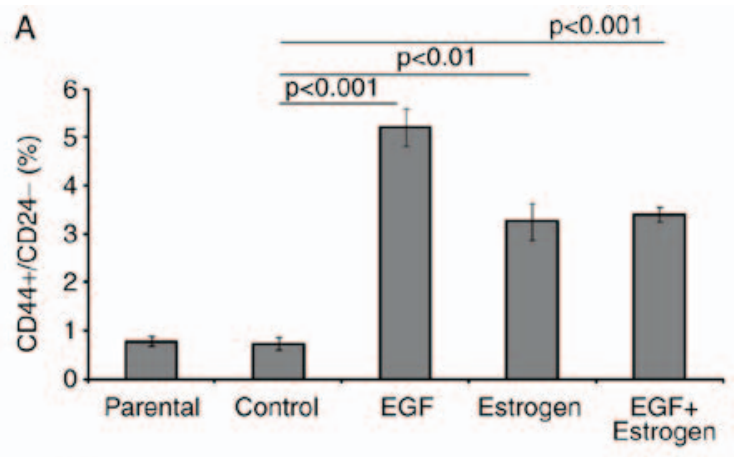

$$
\text { B }
$$
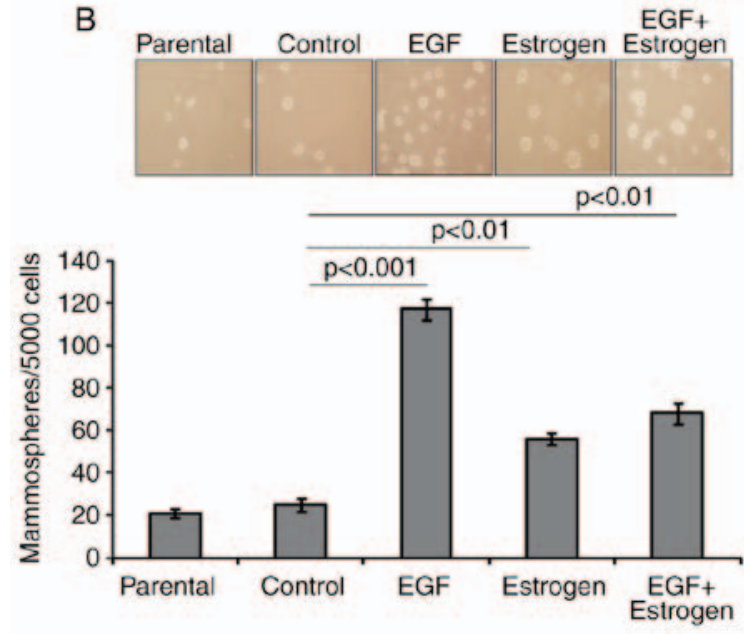

Figure 3. Prolonged EGF and/or 17 $\beta$-estradiol exposure expanded cells with CD $44^{+} / \mathrm{CD} 24^{-}$phenotype. (A) Expression of $\mathrm{CD} 44^{+} / \mathrm{CD} 24^{-}$in EGF- and/or $17 \beta$-estradiol exposed cells was enhanced, compared with that in the control and parental cells. FACS sorting was performed with the same clones used for the xenograft mice experiments. Results are representative of two experiments performed. (B) Increased mammosphere formation was observed for the EGF- and/or 17 $\beta$-estradiol-exposed cells. Images show examples of formed mammospheres (magnification, x100). Results are representative of three experiments performed. Statistical significance of differences in formation of mammospheres was evaluated using a one-way ANOVA with Tukey's HSD. EGF, epidermal growth factor; CD, cluster of differentiation.

A similar but less pronounced pattern of responsiveness was observed for cells exposed to EGF and 17 $\beta$-estradiol (Fig. 4).

The above results suggested that prolonged exposure of human epithelial cells to EGF and/or 17/-estradiol altered the response pattern of the cells to short-term treatments with EGF, $17 \beta$-estradiol, TGF $\beta 1$, and inhibitors of the corresponding signaling pathways (Fig. 4).

\section{Discussion}

The period of time that is required for EGF and estrogen-exposed cells to acquire irreversible changes in tumorigenesis-relevant physiology remains to be elucidated. Short-term treatment, for hours or a few days, may not alter the cells irreversibly, as cancer cells are known to be robust $(32,33)$. Therefore, the length of drug exposure required to induce a sustainable change in cellular physiology is of high relevance for understanding tumorigenesis. The present study demonstrated that drug exposure of MCF7 cells for 40-42 days affected their proliferation rate and transformation phenotype, but was not sufficient to affect tumor growth in mice (Fig. 5).
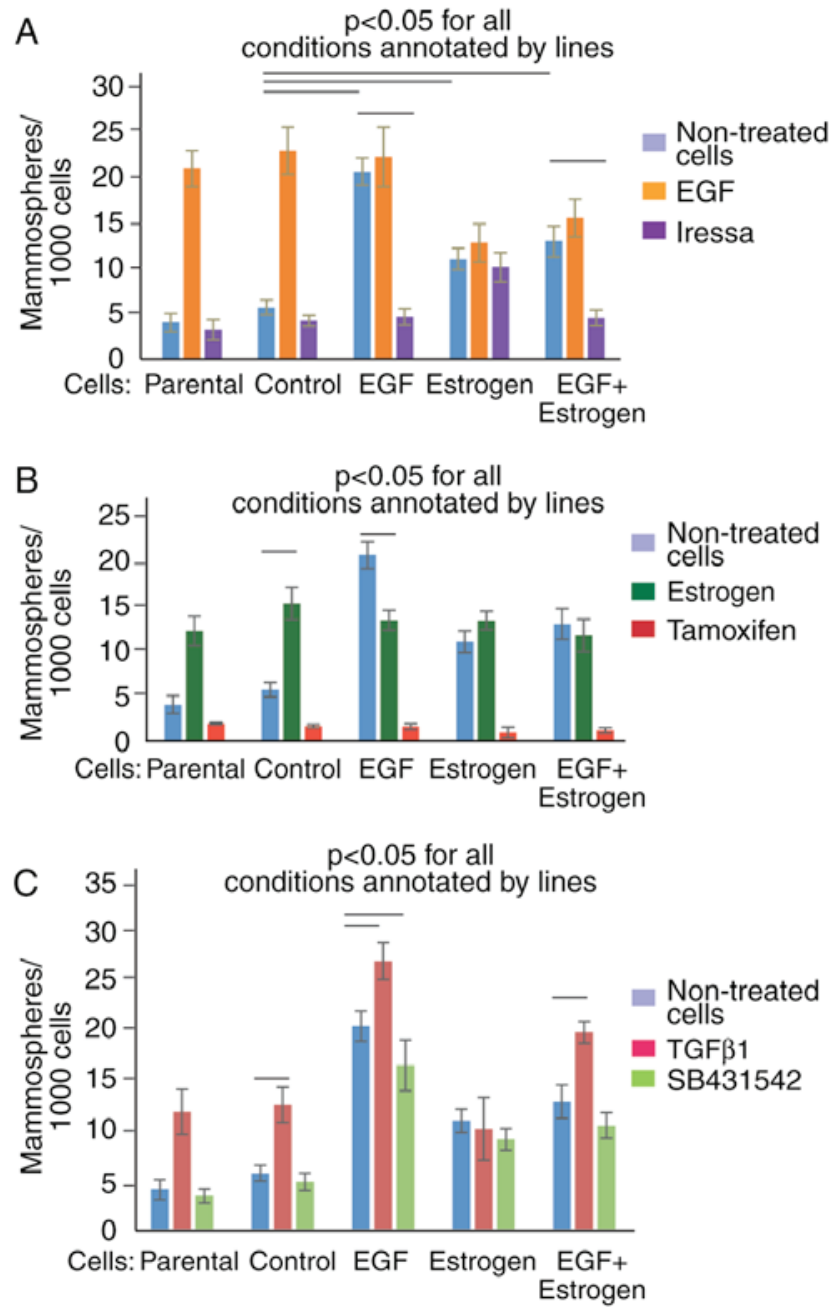

Figure 4. Exposure of cells to EGF and/or 17ß-estradiol changes responsiveness of cells to treatments with TGFb1, Iressa, tamoxifen, and SB431542. Cells groups comprised Parental, Control, EGF, Estrogen (17 $\beta$-estradiol), and EGF + Estrogen (EGF + 17ß-estradiol), as indicated. Cells were treated with (A) EGF and Iressa, (B) estrogen and tamoxifen, and (C) TGF $\beta 1$ and SB431542. The statistical significance of differences was evaluated using a one-way ANOVA with Tukey's HSD. Representative results of three experiments performed are shown. EGF, epidermal growth factor; TGF $\beta$, transforming growth factor- $\beta$.

EGF and $17 \beta$-estradiol are known stimulators of cell proliferation (3-9). The present study observed that prolonged exposure resulted in faster proliferation of MCF7 cells, and this higher rate of proliferation was maintained even upon removal of EGF and 17 $\beta$-estradiol from the medium (Fig. 1). EGF and $17 \beta$-estradiol have been reported to promote tumor formation in mice $(34,35)$. The present study observed that exposure to EGF and 17ß-estradiol for 40-42 days did not affect the take or volume of the formed tumors when the treatments were withdrawn, and the cells injected in the mice were no longer under treatment (Fig. 2). However, immunohistochemistry revealed that exposure to $17 \beta$-estradiol resulted in lower proliferation rate and vascularization. This finding is in agreement with the reported roles of estrogen in the development of breast tissues and breast tumors $(36,37)$. The data obtained in the present study suggested that long-term exposure to drugs did not alter the cellular physiology sufficiently to ensure more marked tumor growth upon withdrawal of treatment. 


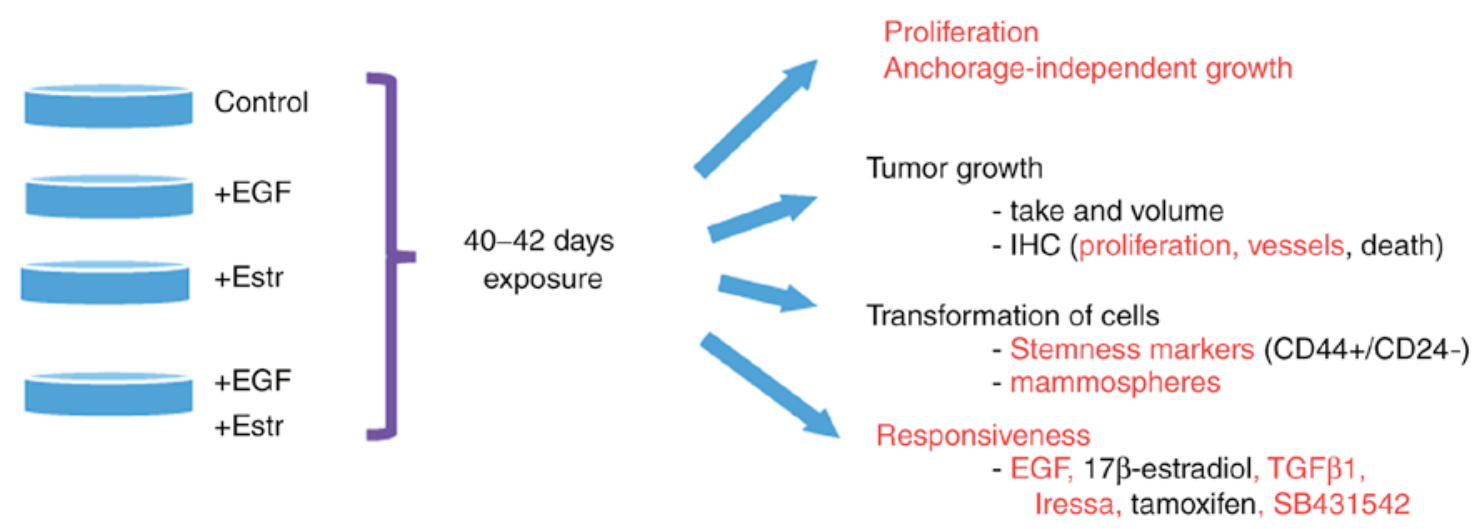

Figure 5. Long-term exposure of MCF7 cells to EGF and/or $17 \beta$-estradiol alters cell proliferation, mammosphere formation, expression of CD44CD24 markers, and responsiveness to treatments, but is not sufficient to affect tumor take or volume in a xenograft mice model. Cellular functions affected by the exposure of cells to EGF and/or 17 $\beta$-estradiol, compared with parental or control cells, are annotated in red. EGF, epidermal growth factor; Estr, $17 \beta$-estradiol; TGF $\beta 1$, transforming growth factor- $\beta 1$; $C D$, cluster of differentiation; IHC, immunohistochemistry.

Cancer stem cells are considered to be responsible for the development of tumors (38). Human breast cancer stem cells can be identified by the expression profile of markers, including CD44 and CD24. The CD44+/CD24- phenotype is characteristic of breast cancer stem cells (38). The present study observed that the fractions of $\mathrm{CD} 44^{+} / \mathrm{CD} 24^{-}$cells followed the pattern of cell proliferation rate and formation of mammospheres (Figs. 1A, 3A and B). This suggested that cell proliferation, the expression of $\mathrm{CD} 44^{+} / \mathrm{CD} 24^{-}$, and mammosphere formation may be early sustainable features induced by carcinogenic exposure to EGF and $17 \beta$-estradiol.

Changes in cellular physiology may have an effect on cellular responsiveness to drugs. The present study evaluated whether the formation of mammospheres was affected upon treatment of the cells with EGF, $17 \beta$-estradiol, TGF $\beta 1$, and drugs that inhibit the corresponding signaling pathways, Iressa, tamoxifen and SB431542 (Fig. 4). As expected, EGF and $17 \beta$-estradiol induced mammosphere formation in parental and control cells, however, this effect was negligible in the EGF- and/or 17 $\beta$-estradiol-exposed cells, and even inhibitory in the EGF-exposed cells treated with $17 \beta$-estradiol. This response may indicate refractoriness of the EGF and $17 \beta$-estradiol signaling pathways. Cells exposed to $17 \beta$-estradiol were less susceptible to the effects of EGF, TGF $\beta 1,17 \beta$-estradiol, Iressa, and SB431542. This result was expected, as treatment with the ligand $17 \beta$-estradiol has been shown to reduce the expression of human epidermal growth factor receptor 2 (HER2) in MCF7 wild-type cells (39). The potent inhibitory effect of tamoxifen on all cells suggested that the MCF7 cells preserved their ER $\alpha$-positive status, thus tamoxifen remained effective independently of the exposure of cells to EGF and 17 $\beta$-estradiol (Fig. 4). The cells exposed to EGF were particularly sensitive to TGF $\beta$-induced proliferation, a clear indicator of crosstalk of these two pathways, for which there is accumulating evidence (40-42). In HER2-transformed cells, TGF $\beta$ further stimulated HER2 signaling to promote malignancy and induced resistance to anti-HER 2 therapy. The observations in the present study showed changes in cellular responsiveness, and confirmed the previously reported promotion of transformation by EGF and TGF $\beta 1$, the stimulatory effect of $17 \beta$-estradiol, and the inhibitory effects of Iressa and tamoxifen $(3-8,43,44)$. The observations also confirmed that long-term exposure may contribute to the development of resistance to Iressa in $17 \beta$-estradiol-exposed cells, and to SB431542 in EGF- and/or $17 \beta$-estradiol-exposed cells.

The response of tumor cells to external stimuli upon short-term treatment induces a number of regulatory processes. However, the majority of these induced responses reverse to the initial state in cells upon withdrawal of the stimulus. The present study hypothesized the existence of stimuli that are long-term effective and/or durable enough to irreversibly alter cellular responsiveness, as cells are robust regulatory systems $(32,33)$. The roles of EGF and estrogen in breast cancer are well documented, and are associated with high levels of signaling as a response to constantly elevated levels of EGF and estrogen as ligands or due to mutations rendering their signaling levels elevated and independent from ligands $(3,4,34-37,42-44)$. The results of the present study suggested that other stimuli may be required in addition to EGF and $17 \beta$-estradiol to promote tumor growth, or that EGF and $17 \beta$-estradiol stimulation may be constantly required during tumor growth. The results demonstrated that exposure to EGF and/or $17 \beta$-estradiol for 40 days was sufficient to alter cell proliferation rate; this transformation was evident in the ability of cells to form mammospheres and express stemness markers, but was not sufficient to affect the rate of tumor growth in mice.

\section{Acknowledgements}

The authors would like to thank Dr Luis Furuya Kanamori for help with statistical analysis. The authors would also like to thank Oves Minnesfond for their support and encouragement.

\section{Funding}

This study was supported in part by grants from the Swedish Institute, the EU program RTN 'EpiPlastCarcinoma' and Erasmus KI-UWM (grant nos. QUST-SPR-2017-12, QUST-SPR-2017-11,NPRP9-453-3-089,HMC-MRC-RP16354 and HMC-MRC-RP-iTRI to SS). 


\section{Availability of data and materials.}

Data and materials are available upon request. There is no data to be deposited in repositories.

\section{Authors' contributions}

All authors contributed equally. SS designed and managed the project, SIC and MJ performed experiments. All authors were involved in writing the manuscript.

\section{Ethics approval and consent to participate}

The animal experiments were performed according to the Swedish national and international guidelines (ethical permit no. C123/6, approved by the Uppsala Animal Tests Committee of the Uppsala Court).

\section{Patient consent for publication}

Not applicable.

\section{Competing interests}

The authors declare that they have no competing interests.

\section{References}

1. PDQ Breast Cancer Treatment. PDQ ${ }^{\circledR}$ Adult Treatment Editorial Board, Bethesda, MD: National Cancer Institute. Updated 10/13/2017. https://www.cancer. gov/types/breast/hp/breast-treatment-pdq. Accessed November 21, 2017. PMID: 26389406, 2017.

2. Patani N, Martin LA and Dowsett M: Biomarkers for the clinical management of breast cancer: International perspective. Int $\mathrm{J}$ Cancer 133: 1-13, 2013.

3. Masuda H, Zhang D, Bartholomeusz C, Doihara H, Hortobagyi GN and Ueno NT: Role of epidermal growth factor receptor in breast cancer. Breast Cancer Res Treat 136: 331-345, 2012.

4. Yue W, Yager JD, Wang JP, Jupe ER and Santen RJ: Estrogen receptor-dependent and independent mechanisms of breast cancer carcinogenesis. Steroids 78: 161-170, 2013.

5. Voudouri K, Berdiaki A, Tzardi M, Tzanakakis GN and Nikitovic D: Insulin-like growth factor and epidermal growth factor signaling in breast cancer cell growth: Focus on endocrine resistant disease. Anal Cell Pathol (Amst) 2015: 975495, 2015.

6. Fouad YA and Aanei C: Revisiting the hallmarks of cancer. Am J Cancer Res 7: 1016-1036, 2017.

7. Margan MM, Jitariu AA, Cimpean AM, Nica C and Raica M: Molecular portrait of the normal human breast tissue and its influence on breast carcinogenesis. J Breast Cancer 19: 99-111, 2016.

8. Hardy KM, Booth BW, Hendrix MJ, Salomon DS and Strizzi L: ErbB/EGF signaling and EMT in mammary development and breast cancer. J Mammary Gland Biol Neoplasia 15: 191-199, 2010.

9. Katzenellenbogen BS and Katzenellenbogen JA: Estrogen receptor transcription and transactivation: Estrogen receptor alpha and estrogen receptor beta: Regulation by selective estrogen receptor modulators and importance in breast cancer. Breast Cancer Res 2: 335-344, 2000.

10. Sukocheva O, Wadham C and Xia P: Estrogen defines the dynamics and destination of transactivated EGF receptor in breast cancer cells: Role of S1Ps receptor and Cdc42. Exp. Cell Res 319: 455-465, 2013.

11. Lichmer RB: Estrogen/EGF receptor interactions in breast cancer: Rationale for new therapeutic combination strategies. Biomed Pharmacother 57: 447-451, 2003.
12. Arpino G, Wiechmann L, Osborne CK and Schiff R: Crosstalk between the estrogen receptor and the HER tyrosine kinase receptor family: Molecular mechanism and clinical implications for endocrine therapy resistance. Endocr Rev 29: 217-233, 2008.

13. Moerkens M, Zhang Y, Wester L, van de Water B and Meerman JHN: Epidermal growth factor receptor signaling in human breast cancer cells operates parallel to estrogen receptor alpha signaling and results in tamoxifen insensitive proliferation. BMC Cancer 14: 283, 2006.

14. Clarke MF, Dick JE, Dirks PB, Eaves CJ, Jamieson CH, Jones DL, Visvader J, Weissman IL and Wahl GM: Cancer stem cells-Perspectives on current status and future directions: AACR workshop on cancer stem cells. Cancer Res 66: 9339-9344, 2006.

15. Al-Hajj M, Wicha MS, Ito-Hernandez A, Morrison SJ and Clarke MF: Prospective identification of tumorigenic breast cancer cells. Proc Natl Acad Sci USA 100: 3983-3988, 2003.

16. Ponti D, Costa A, Zaffaroni N, Pratesi G, Petrangolini G, Coradini D, Pilotti S, Pierotti MA and Daidone MG: Isolation and in vitro propagation of tumorigenic breast cancer cells with stem/progenitor cell properties. Cancer Res 65: 5506-5511, 2005.

17. Fillmore CM and Kuperwasser C: Human breast cancer cell lines contain stem-like cells that self-renew, give rise to phenotypically diverse progeny and survive chemotherapy. Breast Cancer Res 10: 1-13, 2008.

18. Ischenko I, Seeliger H, Schaffer M, Jauch KW and Bruns CJ: Cancer stem cells: How can we target them? Curr Med Chem 15: 3171-3184, 2008

19. Farnie G, Willan PM, Clarke RB and Bundred NJ: Combined inhibition of ErbB1/2 and Notch receptors effectively targets breast ductal carcinoma in situ (DCIS) stem/progenitor cell activity regardless of ErbB2 status. PLos One 8: 0056840, 2013.

20. Asselin-Labat ML, Vaillant F, Sheridan JM, Pal B, Wu D, Simpson ER, Yasuda H, Smyth GK, Martin TJ, Lindeman GJ and Visvader JE: Control of mammary stem cell function by steroid hormone signalling. Nature 465: 798-802, 2010.

21. Fillmore CM, Gupta PB, Rudnick JA, Caballero S, Keller PJ, Lander ES and Kuperwasser C: Estrogen expands breast cancer stem-like cells through paracrine FGF/Tbx3 signaling. Proc Natl Acad Sci USA 107: 21737-21742, 2010.

22. Suurmeijer AJ and Boon M: Pretreatment in a high-presure microwave processor for MIB-immunostaining of cytological smears and paraffin tissue sections to visualize the various phases of the mitotic cycle. J Histochem Cytochem 47: 1015-1020, 1999.

23. Kraby MR, Opdahl S, Akslen LA and Bofin AM: Quantifying tumour vascularity in non-luminal breast cancers. J Clin Pathol 70: 766-774, 2017.

24. Brehm MA: Von Willebrand factor processing. Hamostaseologie 37: 59-72, 2017.

25. Saadin K and White IM: Breast cancer stem cell enrichment and isolation by mammosphere culture and its potential diagnostic applications. Expert Rev Mol Diagn 13: 49-60, 2013.

26. Ishiguro T, Ohata H, Sato A, Yamawaki K, Enomoto T and Okamoto K: Tumor-derived spheroids: Relevance to cancer stem cells and clinical applications. Cancer Sci 108: 283-289, 2017.

27. Saxena R and Dwivedi A: ErbB family receptor inhibitors as therapeutic agents in breast cancer: Current status and future clinical perspective. Med Res Rev 32: 166-215, 2012.

28. Sainsbury R: The development of endocrine therapy for women with breast cancer. Cancer Treat Rev 39: 507-517, 2013.

29. Connolly EC, Freimuth J and Akhurst RJ: Complexities of TGF- $\beta$ targeted cancer therapy. Int J Biol Sci 8: 964-978, 2012.

30. Mints M and Souchelnytskyi S: Impact of combinations of EGF, TGF $\beta, 17 \beta$-oestradiol, and inhibitors of corresponding pathways on proliferation of breast cancer cell lines. Exp Oncol 36: 67-71, 2014.

31. Subik K, Lee JF, Baxter L, Strzepek T, Costello D, Crowley P, Xing L, Hung MC, Bonfiglio T, Hicks DG and Tang P: The Expression Patterns of ER, PR, HER2, CK5/6, EGFR, Ki-67 and AR by immunohistochemical analysis in breast cancer cell lines. Breast Cancer (Auckl) 4: 35-41, 2010.

32. Tian T, Olson S, Whitacre JM and Harding A: The origins of cancer robustness and evolvability. Integr Biol (Camb) 3: 17-30, 2011.

33. Kitano H: Cancer as a robust system: Implications for anticancer therapy. Nat Rev Cancer 4: 227-235, 2004.

34. Kubota T, Josui K, Fukutomi T and Kitajima M: Growth regulation by estradiol, progesterone and recombinant human epidermal growth factor of human breast carcinoma xenografts grown serially in nude mice. Anticancer Res 15: 1275-1278, 1995. 
35. Kenney NJ, Bowman A, Korach KS, Barrett JC and Salomon DS: Effect of exogenous epidermal-like growth factors on mammary gland development and differentiation in the estrogen receptor-alpha knockout (ERKO) mouse. Breast Cancer Res Treat 79: 161-173, 2003.

36. Arendt LM and Kuperwasser C: Form and function: How estrogen and progesterone regulate the mammary epithelial hierarchy. J Mammary Gland Biol Neoplasia 20: 9-25, 2015.

37. Hilakivi-Clarke L, Cabanes A, Olivo S, Kerr L, Bouker KB and Clarke R: Do estrogens always increase breast cancer risk? J Steroid Biochem Mol Biol 80: 163-174, 2002.

38. Da Cruz Paula A and Lopes C: Implications of different cancer stem cell phenotypes in breast cancer. Anticancer Res 37: 2173-2183, 2017.

39. Lattrich C, Juhasz-Boess I, Ortmann O and Treeck O: Detection of an elevated HER2 expression in MCF-7 breast cancer cells overexpressing estrogen receptor beta1. Oncol Rep 19: 811-817, 2008 .
40. Chow A, Arteaga CL and Wang SE: When tumor suppressor TGF $\beta$ meets the HER2 (ERBB2) oncogene. J Mammary Gland Biol Neoplasia 16: 81-88, 2011.

41. Wang SE: The functional crosstalk between HER2 tyrosine kinase and TGF- $\beta$ signaling in breast cancer malignancy. J Signal Transduct 2011: 804236, 2011.

42. Jia M and Souchelnytstkyi S: Comments on the cross-talk of TGF $\beta$ and EGF in cancer. Exp Oncol 33: 170-173, 2011.

43. Yamaoka T, Ohba M and Ohmori T: molecular-targeted therapies for epidermal growth factor receptor and its resistance mechanisms. Int J Mol Sci 18: pii: E2420, 2017.

44. Jameera Begam A, Jubie S and Nanjan MJ: Estrogen receptor agonists/antagonists in breast cancer therapy: A critical review. Bioorg Chem 71: 257-274, 2017. 